\title{
Rehabilitation in Patients with Chronic Respiratory Disease Other than Chronic Obstructive Pulmonary Disease: Exercise and Physical Activity Interventions in Cystic Fibrosis and Non-Cystic Fibrosis Bronchiectasis
}

\author{
Chris Burtin $^{a}$ Helge Hebestreit ${ }^{b}$ \\ ${ }^{a}$ Rehabilitation Research Centre, Biomedical Research Institute, Faculty of Medicine and Life Sciences, Hasselt

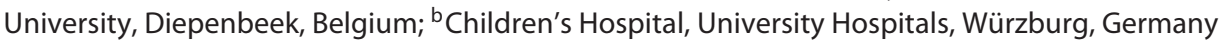

\section{Key Words}

Bronchiectasis · Cystic fibrosis · Exercise · Non-cystic fibrosis bronchiectasis · Physical activity · Rehabilitation

\footnotetext{
Abstract

A relevant proportion of children and adults with cystic fibrosis (CF) have a marked decrease in exercise tolerance, which can be partly related to impaired muscle function and decreased physical activity levels in daily life, in addition to lung disease. Preliminary findings suggest that patients with non-CF bronchiectasis face the same problems. These patients might be excellent candidates for exercise and physical activity interventions. This review elaborates on the rationale for exercise training and activity behaviour

Previous articles in this series: 1. Osadnik CR, Rodrigues FMM, Camillo CA, Loeckx M, Janssens W, Dooms C, Troosters T: Principles of rehabilitation and reactivation. Respiration 2015;89:2-11. 2. Holland AE, Dowman LM, Hill CJ: Principles of rehabilitation and reactivation: interstitial lung disease, sarcoidosis and rheumatoid disease with respiratory involvement. Respiration 2015;89:89-99.
}

\section{KARGER 125}

() 2015 S. Karger AG, Basel

0025-7931/15/0893-0181\$39.50/0

E-Mail karger@karger.com

www.karger.com/res changes and summarizes the existing evidence for these rehabilitation strategies in patients with bronchiectasis, both CF and non-CF bronchiectasis. Furthermore, practical considerations and safety aspects are discussed.

(C) 2015 S. Karger AG, Basel

\section{Introduction}

Bronchiectasis can be described as an abnormal dilatation of bronchi and bronchioles due to recurrent or prolonged airway infection and inflammation [1]. Recurrence of airway infection and inflammation leads to airway damage that results in further infection and, ultimately, airway and lung parenchyma destruction [2]. Consequently, bronchiectasis is associated with loss of lung function and may result in chronic comorbidity and early mortality [3]. A diagnosis of an underlying condition causing bronchiectasis can be made in approximately $50 \%$ of cases [4]. Frequently, a distinction is made between bronchiectasis caused by cystic fibrosis (CF) and non-CF bronchiectasis. 
CF is an autosomal-recessive disease caused by mutations in the CF transmembrane conductance regulator (CFTR) gene [5]. The resulting dysfunction in the CFTR protein, a chloride channel, affects multiple body systems, including the respiratory and gastrointestinal tract. Chronic infections of the lower airways in combination with the resulting inflammatory response induce bronchiectasis. Clinically, bronchial secretions are excessively thick, respiratory mechanics and gas exchange are altered, and lung function decreases [6]. Patients periodically suffer from exacerbations, i.e. acute deteriorations in respiratory symptoms that are associated with decreases in quality of life and lung function, and increased mortality $[7,8]$.

Non-CF bronchiectasis includes all patients with bronchiectasis in whom $\mathrm{CF}$ has been ruled out as diagnosis. Multiple underlying causes have been identified, including infections, congenital conditions such as immunodeficiency or primary cilia dyskinesia, and inflammatory bowel disease [9]. The available evidence concerning indications and effectiveness of exercise and physical activity interventions is very limited in patients with nonCF bronchiectasis. This review focuses on the existing knowledge in patients with CF, supplemented with information about non-CF bronchiectasis if available.

\section{Exercise Intolerance}

Exercise intolerance is a hallmark feature of CF. Numerous protocols have been used to assess aerobic exercise capacity in people with CF and non-CF bronchiectasis. These tests include field tests, such as the 6-min walking test or shuttle run tests as well as full cardiopulmonary exercise tests [10]. An international expert group recently recommended the Godfrey cycle protocol including gas exchange measurements as preferred option for the assessment of patients with CF. The Godfrey cycle protocol with pulse oximetry or treadmill testing is considered the second best option. For anaerobic testing, which is not part of routine clinical assessment, the Wingate Anaerobic Test has most often been employed [11].

Peak aerobic capacity $\left(\mathrm{VO}_{2_{\max }}\right)$, anaerobic capacity (e.g. performance in the Wingate test) and functional exercise tolerance (e.g. 6-min walking test) are below normal in many adults and some children with stable CF, even after correction for lean body mass [12-14]. Troosters et al. [13] reported that $75 \%$ of adult patients with stable CF (mean $\mathrm{FEV}_{1} 65 \%$ of the predicted value) have a 6 -min walking distance below the limits of normal, while up to

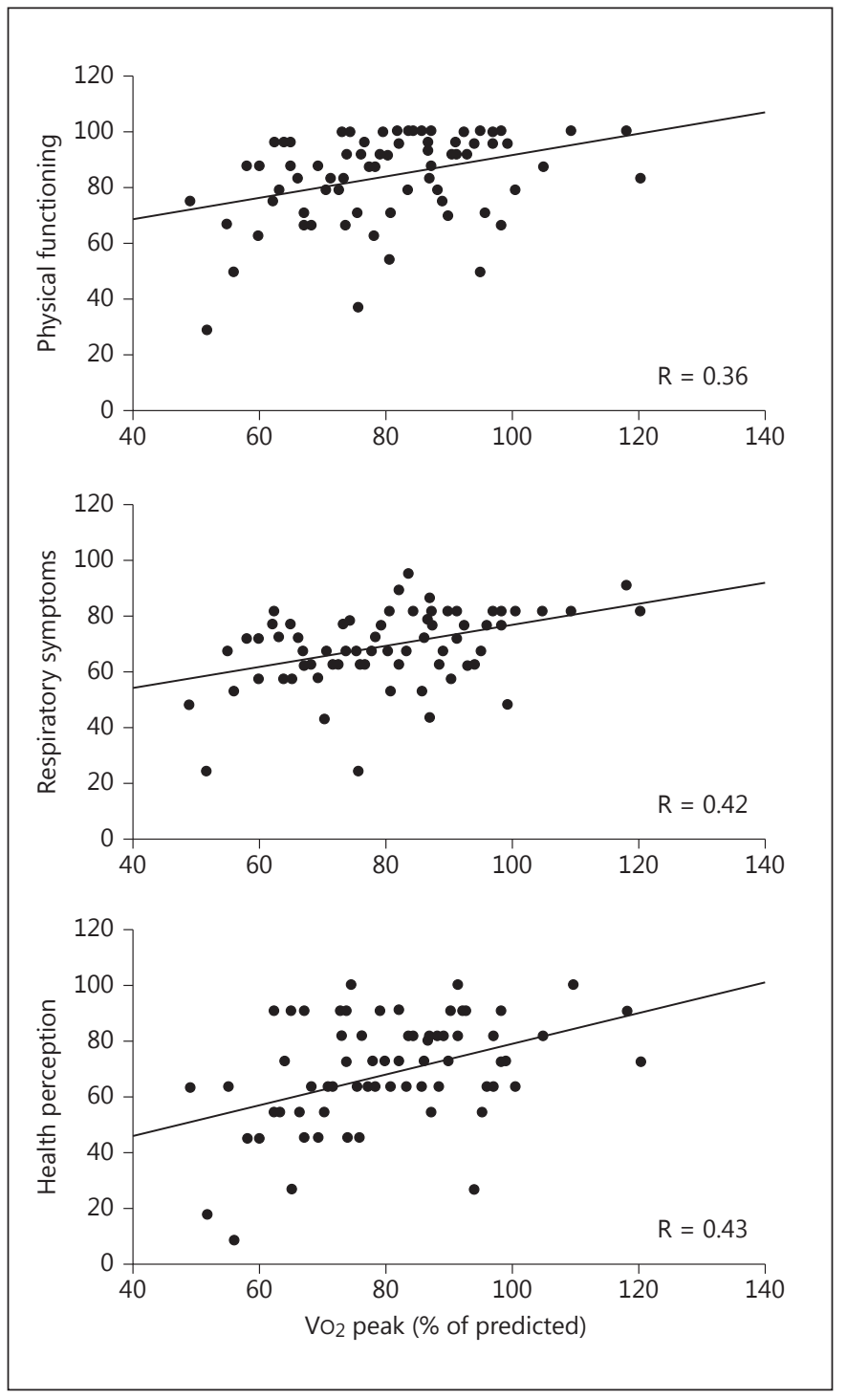

Fig. 1. Relationship between different domains in the disease-specific, health-related quality-of-life questionnaire CFQ-R and aerobic fitness in 76 patients with CF (data from Hebestreit et al. [19]).

$90 \%$ of these patients showed a decreased peak aerobic capacity. A decreased 6-min walking distance has also been reported in non-CF bronchiectasis [15].

Low peak aerobic capacity and peak work rate are linked to higher mortality rates across the age range of $\mathrm{CF}$ patients $[16,17]$. Exercise intolerance is also independently associated to loss of bone mineral density [18] and quality of life (fig. 1) [19]. Changes in aerobic exercise capacity after treatment are associated with changes in quality of life $[19,20]$. 


\section{Reasons for a Reduced Exercise Capacity}

Patients with advanced lung disease experience static and dynamic hyperinflation due to airflow limitation, leading to reduced tidal volumes, increased dead space ventilation and exertional dyspnoea [21,22]. Even though the relationship between aerobic performance on the one hand and both lung pathology and lung function (at rest and during exercise) on the other hand has been clearly established [14,21,23-25], the aetiology of exercise intolerance is multifactorial. In light of this, Dodd et al. [26] showed that inhaled $\beta$-agonists are able to improve lung function but do not enhance performance during a cardiopulmonary exercise test.

Children with CF and only class I and II mutations have lower aerobic and/or anaerobic exercise capacity compared to children with at least one class III, IV or V mutation, independent of lung function, with the underlying mechanisms remaining to be determined [27]. In some patients, cardiovascular abnormalities might play a role, as a decreased left ventricular diastolic function (in patients with advanced disease) and lower stroke volume for a given $\mathrm{VO}_{2}$ have been reported $[28,29]$.

Furthermore, in a large sample of adult CF, Moorcroft et al. [30] showed that patients have decreased exercise tolerance, but response to exercise was similar to that of healthy controls. They generated high blood lactate concentrations but at lower levels of exercise. Furthermore, these patients reported muscle effort scores in excess of dyspnoea scores. This suggests the involvement of peripheral muscles in the impairment to exercise. This muscle impairment might be $\mathrm{CF}$ specific or due to decreased levels of daily physical activity.

Peripheral muscle weakness is prevalent in children and adult patients with CF $[13,31,32]$. Quadriceps strength is decreased by $25-35 \%$ in comparison with agematched healthy adults $[13,31]$. Even though muscle function is suggested to be close to normal in highly active patients [33], Selvadurai et al. [34] have shown that female athletes with CF may still have deficits in peak anaerobic power and muscle metabolism. Multiple factors have been identified to be involved in the onset of muscle dysfunction. The decrease in skeletal muscle mass and muscle strength is proportional, indicating that the quality of the contractile structures remains intact in these patients [13, 31]. However, muscle metabolism seems to be impaired, especially during high-intensity exercises [35]. Malnutrition and electrolyte disturbances [36], physical inactivity [13,25], systemic inflammation [37], oxidative stress [38], oral corticosteroid use [39] and CF- specific gene defects $[35,40,41]$ are suggested to be involved in muscle dysfunction. Frequent exacerbations might further play a role in the long-term development of muscle dysfunction. Quadriceps maximal voluntary strength decreases acutely when admitted for an exacerbation [42]. Even though voluntary strength generally recovers throughout hospital stay and follow-up [42], nonvolitional assessment of quadriceps strength detects a further decrease during hospitalization [43]. This decrease is associated with the time spent in activities of at least moderate intensity but not with blood parameters of systemic inflammation.

A high proportion of patients with non-CF bronchiectasis present with fat-free mass depletion regardless of the aetiology of the disease [44]. This depletion is linked to increased systemic inflammation. To the authors' knowledge, information about specific muscle strength is not yet available in non-CF bronchiectasis.

Diaphragm strength may also be decreased in CF despite a normal muscle bulk, suggesting that the functional changes in diaphragm position due to hyperinflation place this muscle into a disadvantage $[31,45]$. In contrast, abdominal strength is increased in CF patients, suggesting a training effect due to frequent coughing [31].

Physical activity levels seem to be well preserved in pre-pubescent and pubescent children with mild disease, but decrease in pubescent children with moderate or severe disease [46]. After puberty, females are typically less active compared to males [46, 47], reflecting similar observations in the healthy population. In adult patients, the amount of steps per day is similar to a sedentary healthy sample, but the time spent in at least moderate-intensity activities ( $>4.8$ metabolic equivalents, e.g. brisk walking or cycling) is decreased [13]. Moderate-intensity activities are typically considered necessary to maintain physical fitness [48]. In non-CF bronchiectasis, objective outcomes of physical activity are not available, but self-reported physical activity is also decreased [15].

High levels of physical activity are related to higher quality of life [46], higher aerobic capacity [25] and better-preserved bone density [49]. Furthermore, recent evidence suggests that highly active patients experience a slower decline in $\mathrm{FEV}_{1}$ over a 9-year period [50].

\section{Exercise Interventions}

Muscle weakness and physical inactivity provide a clear rationale for exercise training and physical activity interventions. Exercise interventions should be embed- 
Fig. 2. Effect of home-based exercise intervention on the annual change in FVC and $\mathrm{FEV}_{1}$ in three randomized controlled trials lasting at least 1 year: data from Schneiderman-Walker et al. [59] (2000) and Hebestreit et al. [61] (2010) are expressed in percent of predicted, and those from Moorcroft et al. [60] (2004) in millilitre.

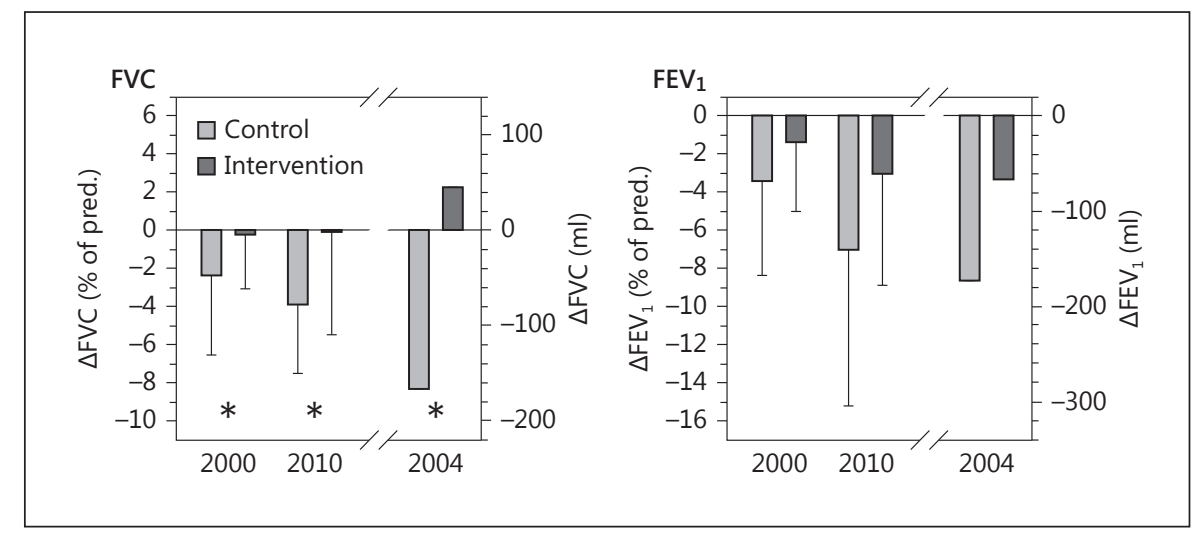

ded in a multidisciplinary approach, including medical supervision, nutritional and psychosocial management, self-management strategies and mucus clearance techniques, which are tailored to the individual patient [51]. This review focuses on the exercise component of multidisciplinary care. Exercise is now considered an essential component of the integral CF management [52-54] and is effective in improving physical fitness, pulmonary function and health-related quality of life [55].

The high-quality evidence supporting the effectiveness of exercise interventions includes supervised programmes in an inpatient [56], outpatient [57] or community setting [58], and partially or unsupervised homebased programmes [59-62]. Specific activity guidelines do not exist in patients with CF, but most described programmes include moderate- to high-intensity aerobic training (generally ranging between 60 and $80 \%$ of peak capacity) and/or resistance training [56, 58, 59, 62]. Even though both modalities have the potential to improve physical fitness and pulmonary function (assessed by $\mathrm{FVC}$ and $\mathrm{FEV}_{1}$; fig. 2) [58-61], a combination of both modalities might provide the most optimal effect. In line with the training principle of specificity, aerobic exercises are associated with a more enhanced increase in aerobic capacity while resistance training better targets muscle strength deficits [56]. Aerobic training might be especially indicated in patients with decreased endurance capacity, while patients with profound muscle weakness might benefit greatly from resistance training. In patients with inspiratory muscle weakness, inspiratory muscle training has been considered as a training modality. Unfortunately, evidence to support or reject this intervention is still lacking in CF [63].

In patients with non-CF bronchiectasis, two randomized controlled trials evaluating the outcomes of 8 weeks of moderate- to high-intensity aerobic exercise training showed significant improvements in terms of wholebody endurance capacity and incremental shuttle walk test performance $[64,65]$. In one of these studies, benefits in disease-related quality of life were only obtained if inspiratory muscle training was added to the exercise training programme [64]. Retrospective analysis suggests that exercise training has the potential to enhance forced vital capacity and residual volume in patients with idiopathic bronchiectasis specifically [66]. However, these findings need to be confirmed in prospective controlled trials.

In patients with severe disease that are unable to perform moderate-intensity aerobic exercise, interval training could provide a safe alternative, which is perceived less strenuous but is still effective in improving aerobic capacity. On the other side of the interval training spectrum, Klijn et al. [57] investigated the effectiveness of a 3-month high-intensity interval training programme, consisting of anaerobic 20- to 30-second exercise bursts, such as sprint running, hurdles, lifting and throwing heavy balls. They reported an increase in anaerobic capacity and quality of life, which was sustained during the 3-month follow-up. Interestingly, aerobic capacity was also increased in the short term but not during follow-up.

\section{Exercise-Related Risks}

While there is accumulating evidence for the benefits of regular intense activity in people with bronchiectasis, very little has been reported on adverse events associated with exercise. Nearly all of this information is related to CF. 
From a patients' perspective, adverse reactions to exercise may include dyspnoea, productive cough and fatigue. Quite often, these observations are normal reactions to exertion which will lead to adaptive responses with regular training, i.e. less exercise-induced dyspnoea and less fatigue. The productive cough may also decrease with training and airway clearance before exercise can further reduce symptoms. However, in some cases, the exercise volume or intensity need to be limited.

When patients are exercising together, the risk of cross-contamination should always be considered [67]. General guidelines on cohort segregation, hand hygiene and environmental cleaning and disinfection should also be applied in this setting [68]. In light of this, thorough patient education is essential.

Some adverse reactions to exercise affecting the pulmonary system as well as other organ systems in people with bronchiectasis are further discussed in more detail.

\section{Exercise-Induced Bronchoconstriction}

Some patients with CF and non-CF bronchiectasis suffer from exercise-induced bronchoconstriction $[69,70]$. It is unclear whether this adverse reaction to exercise is more common than in the general population, and no studies have systematically assessed the best prevention measures or treatment. Although some information suggests that exercise-induced bronchial constriction in $\mathrm{CF}$ may be different from that in bronchial asthma [70,71], drugs used to treat bronchial asthma, such as $ß$-agonists and inhaled steroids, are often used. Nevertheless, their effectiveness should be assessed on an individual basis.

There are also no data on the effectivity of anti-leukotrienes in the prevention of exercise-induced bronchoconstriction in patients with CF or non-CF-bronchiectasis. However, a recent report of a randomized controlled trial in CF indicates a higher incidence of pulmonary exacerbations in adult patients actively treated with a leukotriene $\mathrm{B} 4$ receptor antagonist [72].

\section{Exercise-Induced Hypoxaemia}

Exercise-induced hypoxaemia is often defined as a drop in oxygen saturation by more than 4 or below $90 \%$. It is observed in about $20-25 \%$ of all patients with CF [73, 74]. Likewise, nearly $30 \%$ of adolescents with vertically acquired HIV infection, many of whom showed bronchiectasis on CT scans, had exercise-induced hypoxaemia; in addition, 13\% had hypoxaemia at rest [75].

Although exercise-induced hypoxaemia is more common in patients with decreased lung function, patients cannot be identified by spirometry alone [74]. Thus, ex-

Physical Activity in CF and Non-CF

Bronchiectasis ercise testing is required for the diagnosis of exercise-induced hypoxaemia.

Although conclusive data are lacking, it has been recommended that a prolonged period with an oxygen saturation of less than $90 \%$ may pose a risk to patients and should, therefore, be avoided [76]. Restrictions in exercise intensity, interval training and supplemental oxygen with exercise have all been used to prevent exercise-induced hypoxaemia in people with chronic lung disease.

\section{Pneumothorax}

Up to $4 \%$ of CF patients will suffer from a pneumothorax during their life span [77]. Risk factors include older age, poor pulmonary function and infections [77]. However, there is also anecdotal evidence that exercise, and especially high intrathoracic pressure with pressure breath hold during weight training, may lead to a pneumothorax [78].

There is some consensus to withhold exercise after a pneumothorax has occurred [79]. However, there is no guideline on when to restart exercise after a pneumothorax. It has been suggested that once pneumothorax has resolved and the chest tube is removed, light leg exercises may be started under close supervision, and intensity may then be gradually increased [80]. If no complications occur, upper body exercises might be introduced 2-4 weeks after removal of the chest drain.

\section{Haemoptysis}

Some streaks of blood are not uncommon in the sputum of CF patients. Massive haemoptysis is about as common as pneumothorax, affecting about $4 \%$ of patients [81]. Risk factors for haemoptysis are similar to those of pneumothorax, and exercise may trigger haemoptysis. While some but not all experts would recommend to stop exercise with mild or moderate haemoptysis, most physicians would strongly advise against exercise when massive haemoptysis occurs [79].

\section{Cardiac Arrhythmia}

About $5-10 \%$ of patients will experience cardiac arrhythmias with exercise [74]. Patients at risk are those with exercise-induced hypoxaemia (see Exercise-Induced Hypoxaemia). Whether oxygen supplementation or restriction of exercise intensity is effective to prevent cardiac arrhythmias has not been studied.

Chronic therapy with macrolides - which is quite common in patients with bronchiectasis - has also been linked to ventricular arrhythmia [82]. Whether such treatment is also associated with exercise-induced cardiac arrhythmia is not known. 


\section{Sprains, Strains and Fractures}

As in the healthy population, exercise is associated with a certain risk for injuries. Conceivably, the risk for fractures should even be increased in people with CF given the relatively high incidence of osteopaenia and osteoporosis in this population [83]. However, a recent survey found a surprisingly low incidence of fractures with exercise in CF [78].

Other populations who are likely to develop bronchiectasis, such as patients with common variable immunodeficiency, have also an increased risk for osteopaenia [84]. Whether this condition predisposes to fractures is not known.

\section{Other Exercise-Related Risks Specific to CF}

In $\mathrm{CF}$, in addition to the pulmonary system, many other organ systems are also affected. Therefore, adverse events may occur which are specific to CF. These include fluid and electrolyte losses from sweating [85]; injury to the spleen and oesophageal haemorrhage in patients with portal hypertension, and hypoglycaemia in patients with CF-related diabetes mellitus [78]. Nevertheless, exercise is possible and encouraged for all patients with CF but requires appropriate guidance [86], i.e. recommending appropriate fluid and salt intake when exercising in the heat, abstaining from injury-prone activities if portal hypertension is present, and training how to avoid hypoglycaemia by carbohydrate intake and/or adjusting insulin doses before or during exercise [87]. Furthermore, arthritis, another comorbidity of CF, may be worsened with exercise [78].

\section{Risk-Benefit Ratio}

Although the preceding list of potential exercise-related risks may appear large, true adverse events with exercise are rare and mainly affect patients with advanced disease [73]. Risks may further be limited by individual assessments, including standardized exercise testing and appropriate guidance. It is the clear understanding of the authors of this publication, but also of many other clinicians responsible for patient care, that exercise-related benefits outweigh the potential risks $[51,52]$.

\section{Towards a Physically Active Lifestyle}

Even though exercise training programmes have a crucial role in the rehabilitation of deconditioned patients, beneficial effects wear off quickly if the patient does not continue exercises on a longer term. It is of utmost importance to translate an increase in physical capacity into a behavioural change towards a physically active lifestyle. A recent Cochrane review focusing on interventions to promote physical activity behaviour in patients with $\mathrm{CF}$ indicated that long-term home exercise programmes, including physical activity counselling and exercise advice, may be needed to really influence activity participation in these patients [88]. Partially supervised home exercise programmes might be an interesting approach to incorporate regular exercise into daily life. SchneidermanWalker et al. [59] submitted patients to a 3-year home exercise programme, consisting of three weekly 20 -min sessions of moderate- to high-intensity aerobic activity. In order to optimize adherence, regular telephone contacts were scheduled and incentives like sport bags and T-shirts were included. Despite a lack of effect in terms of maximal aerobic capacity, the authors reported increased self-reported activity scores throughout the 3-year period, and compliance with the exercise programme remained high during the study [59]. Interestingly, the intervention also had a protective effect on FVC decline during the 3-year period. These findings were confirmed by Hebestreit et al. [61] during their 12- to 18-month follow-up after a physical activity intervention, consisting of 3 additional hours of sports per week for at least 6 months, which were supported by three activity counselling sessions. They reported improvements in maximal aerobic capacity, time spent in vigorous intense physical activity levels, quality of life and FVC after follow-up compared to baseline [61].

The findings of Schneiderman-Walker et al. [59] and Hebestreit et al. [61] suggest a direct association between a physically inactive lifestyle and disease progression. The underlying mechanisms are not fully elucidated and might be multifactorial. First, exercise results in an increased sputum expectoration [89], possibly due to increased ventilation, the induction of whole-body vibrations or slightly enhanced bronchodilation based on increased release of catecholamines [90]. Second, exercise might exhibit an anti-inflammatory response enhancing the immune system [91]. However, the amount of evidence supporting this hypothesis is still very limited. Third, exercise possibly improves pathophysiological ion dysregulation via adrenergic and purinergic pathways [92].

Adherence to physical activity is a major challenge in patients with CF. The proportion of patients reporting to be fully adherent to exercise as part of their routine care is lower than $25 \%$ [93]. Interestingly, patients tend to re- 
port that chest physiotherapy is important, but exercise is not. In light of the high treatment burden - a large sample of adult patients reported to spend a mean of $108 \mathrm{~min}$ per day on treatment activities [94] - the motivation to perform exercise is likely diminished. Nevertheless, adherence to exercise is better in comparison to adherence to airway clearance techniques. Barriers that might prevent people from exercising include the onset of general discomfort and increased lung symptoms, disinterest and competing activities, priorities and responsibilities [95, 96]. In order to overcome these barriers, a simple prescription of exercise is likely not enough. Physical activity counselling is a promising intervention that can support patients individually during the process of behavioural changes [61]. During these counselling sessions, the benefits of exercise can be clarified, barriers can be identified and discussed, and action plans can be formulated. Parents can be involved to enhance social support. Feedback from objective measurements of physical activity could possibly be used to motivate and reinforce patients throughout the behavioural changes [97]. Given the high treatment burden, it appears crucial that the physical activity component is pleasant and rewarding, and is ideally considered as a hobby in the long term. The beneficial long-term results in terms of interventions to promote physical activity behaviour that engaged people to perform a self-chosen sport clearly illustrate this [61]. As the paediatric and young adult population increasingly spends time using computers and playing video games, gaming consoles will probably become popular tools to incorporate physical activity aspects in daily life. During active gaming, the cardiovascular demand can be similar to cycle or treadmill exercises [98], with peak heart rates ranging from 80 to $90 \%$ of maximal heart rate [99]. The effectiveness of this promising and continuously developing intervention remains to be established. Furthermore, some applications for mobile phones are effective motivational tools to improve exercise adherence. Such software - using GPS signals - can track the (daily) run, including the distance covered, velocity or meters climbed, for example, and can show the course on a map. Other applications can provide guidance on improving abdominal muscle bulk. In any case, it is important to give individual guidance to a patient to reduce risky behaviour and focus on whole-body conditioning. Increasing muscular dysbalances should be avoided.

\section{Conclusion}

Exercise programs improve physical fitness of patients with $\mathrm{CF}$ and non-CF bronchiectasis. Further benefits include a stabilization of pulmonary function and improvements in quality of life. Home-based interventions which focus on enjoyable activities may be most promising in the long run. Since adverse reactions to exercise may occur, individual counselling based on medical history, physical examination and further assessments, including exercise testing, are of high importance.

\section{References}

1 Barker AF: Bronchiectasis. N Engl J Med 2002;346:1383-1393.

2 Morrissey BM: Pathogenesis of bronchiectasis. Clin Chest Med 2007;28:289-296.

- 3 King PT, Holdsworth SR, Freezer NJ, et al: Outcome in adult bronchiectasis. COPD 2005;2:27-34.

4 O'Donnell AE: Bronchiectasis. Chest 2008; 134:815-823.

5 Riordan JR, Rommens JM, Kerem B, et al: Identification of the cystic fibrosis gene: cloning and characterization of complementary DNA. Science 1989;245:1066-1073.

-6 O'Sullivan BP, Freedman SD: Cystic fibrosis. Lancet 2009;373:1891-1904.

7 Britto MT, Kotagal UR, Hornung RW, et al: Impact of recent pulmonary exacerbations on quality of life in patients with cystic fibrosis. Chest 2002;121:64-72.
8 de BK, Vandemheen KL, Tullis E, et al: Exacerbation frequency and clinical outcomes in adult patients with cystic fibrosis. Thorax 2011;66:680-685.

9 Goeminne P, Dupont L: Non-cystic fibrosis bronchiectasis: diagnosis and management in 21st century. Postgrad Med J 2010;86:493501.

10 Radtke T, Stevens D, Benden C, et al: Clinical exercise testing in children and adolescents with cystic fibrosis. Pediatr Phys Ther 2009; 21:275-281.

11 Klijn PH, Terheggen-Lagro SW, van der Ent $\mathrm{CK}$, et al: Anaerobic exercise in pediatric cystic fibrosis. Pediatr Pulmonol 2003;36:223229.

12 de Meer K, Gulmans VA, van Der Laag J: Peripheral muscle weakness and exercise capacity in children with cystic fibrosis. Am J Respir Crit Care Med 1999;159:748-754.
13 Troosters T, Langer D, Vrijsen B, et al: Skeletal muscle weakness, exercise tolerance and physical activity in adults with cystic fibrosis. Eur Respir J 2009;33:99-106.

14 Cabrera ME, Lough MD, Doeshuk CF, et al: Anaerobic performance assessed by the Wingate Test in patients with cystic fibrosis. Pediatr Exerc Sci 1993;5:78-87.

15 Gale NS, Bolton CE, Duckers JM, et al: Systemic comorbidities in bronchiectasis. Chron Respir Dis 2012;9:231-238.

16 Moorcroft AJ, Dodd ME, Webb AK: Exercise testing and prognosis in adult cystic fibrosis. Thorax 1997;52:291-293.

17 Nixon PA, Orenstein DM, Kelsey SF, et al: The prognostic value of exercise testing in patients with cystic fibrosis. N Engl J Med 1992; 327:1785-1788.
Physical Activity in CF and Non-CF

Bronchiectasis
Respiration 2015;89:181-189 DOI: $10.1159 / 000375170$ 
18 Dodd JD, Barry SC, Barry RB, et al: Bone mineral density in cystic fibrosis: benefit of exercise capacity. J Clin Densitom 2008;11:537542.

19 Hebestreit H, Schmid K, Kieser S, et al: Quality of life is associated with physical activity and fitness in cystic fibrosis. BMC Pulm Med 2014;14:26.

20 Bradley J, McAlister O, Elborn S: Pulmonary function, inflammation, exercise capacity and quality of life in cystic fibrosis. Eur Respir J 2001;17:712-715.

21 Alison JA, Regnis JA, Donnelly PM, et al: End-expiratory lung volume during arm and leg exercise in normal subjects and patients with cystic fibrosis. Am J Respir Crit Care Med 1998;158:1450-1458.

22 Perpati G, Nanas S, Pouliou E, et al: Resting respiratory variables and exercise capacity in adult patients with cystic fibrosis. Respir Med 2010;104:1444-1449.

23 Klijn PH, van der Net J, Kimpen JL, et al: Longitudinal determinants of peak aerobic performance in children with cystic fibrosis. Chest 2003; 124:2215-2219.

24 Dodd JD, Barry SC, Barry RB, et al: Thin-section CT in patients with cystic fibrosis: correlation with peak exercise capacity and body mass index. Radiology 2006;240:236-245.

25 Hebestreit H, Kieser S, Rudiger S, et al: Physical activity is independently related to aerobic capacity in cystic fibrosis. Eur Respir J 2006;28:734-739.

26 Dodd JD, Barry SC, Daly LE, et al: Inhaled beta-agonists improve lung function but not maximal exercise capacity in cystic fibrosis. J Cyst Fibros 2005;4:101-105.

-27 Selvadurai HC, McKay KO, Blimkie CJ, et al: The relationship between genotype and exercise tolerance in children with cystic fibrosis. Am J Respir Crit Care Med 2002;165:762-765.

28 Pianosi P, Pelech A: Stroke volume during exercise in cystic fibrosis. Am J Respir Crit Care Med 1996;153:1105-1109.

29 Koelling TM, Dec GW, Ginns LC, et al: Left ventricular diastolic function in patients with advanced cystic fibrosis. Chest 2003;123: 1488-1494.

-30 Moorcroft AJ, Dodd ME, Morris J, et al: Symptoms, lactate and exercise limitation at peak cycle ergometry in adults with cystic fibrosis. Eur Respir J 2005;25:1050-1056.

31 Pinet C, Cassart M, Scillia P, et al: Function and bulk of respiratory and limb muscles in patients with cystic fibrosis. Am J Respir Crit Care Med 2003;168:989-994.

- 32 Hussey J, Gormley J, Leen G, et al: Peripheral muscle strength in young males with cystic fibrosis. J Cyst Fibros 2002;1:116-121.

-33 Sahlberg ME, Svantesson U, Thomas EM, et al: Muscular strength and function in patients with cystic fibrosis. Chest 2005; 127:15871592.

34 Selvadurai HC, Allen J, Sachinwalla T, et al: Muscle function and resting energy expenditure in female athletes with cystic fibrosis. Am J Respir Crit Care Med 2003;168:1476-1480.
35 Wells GD, Wilkes DL, Schneiderman JE, et al: Skeletal muscle metabolism in cystic fibrosis and primary ciliary dyskinesia. Pediatr Res 2011;69:40-45.

36 Gupta A, Eastham KM, Wrightson N, et al: Hypomagnesaemia in cystic fibrosis patients referred for lung transplant assessment. J Cyst Fibros 2007;6:360-362.

37 Ionescu AA, Nixon LS, Luzio S, et al: Pulmonary function, body composition, and protein catabolism in adults with cystic fibrosis. Am J Respir Crit Care Med 2002;165:495-500.

38 Wood LG, Fitzgerald DA, Gibson PG, et al: Oxidative stress in cystic fibrosis: dietary and metabolic factors. J Am Coll Nutr 2001; 20(suppl 2):157-165.

-39 Barry SC, Gallagher CG: Corticosteroids and skeletal muscle function in cystic fibrosis. J Appl Physiol (1985) 2003;95:1379-1384.

40 Lamhonwah AM, Bear CE, Huan LJ, et al: Cystic fibrosis transmembrane conductance regulator in human muscle: dysfunction causes abnormal metabolic recovery in exercise. Ann Neurol 2010;67:802-808.

41 Divangahi M, Balghi $\mathrm{H}$, Danialou G, et al: Lack of CFTR in skeletal muscle predisposes to muscle wasting and diaphragm muscle pump failure in cystic fibrosis mice. PLoS Genet 2009;5:e1000586.

42 Wieboldt J, Atallah L, Kelly JL, et al: Effect of acute exacerbations on skeletal muscle strength and physical activity in cystic fibrosis. J Cyst Fibros 2012;11:209-215.

43 Burtin C, Van RH, Vrijsen B, et al: Impact of exacerbations of cystic fibrosis on muscle strength. Respir Res 2013;14:46.

44 Olveira G, Olveira C, Gaspar I, et al: Fat-free mass depletion and inflammation in patients with bronchiectasis. J Acad Nutr Diet 2012; 112:1999-2006

45 Ionescu AA, Chatham K, Davies CA, et al: Inspiratory muscle function and body composition in cystic fibrosis. Am J Respir Crit Care Med 1998;158:1271-1276.

46 Selvadurai HC, Blimkie CJ, Cooper PJ, et al: Gender differences in habitual activity in children with cystic fibrosis. Arch Dis Child 2004; 89:928-933.

47 Schneiderman-Walker J, Wilkes DL, Strug L, et al: Sex differences in habitual physical activity and lung function decline in children with cystic fibrosis. J Pediatr 2005;147:321-326.

48 Garber CE, Blissmer B, Deschenes MR, et al: American College of Sports Medicine position stand. Quantity and quality of exercise for developing and maintaining cardiorespiratory, musculoskeletal, and neuromotor fitness in apparently healthy adults: guidance for prescribing exercise. Med Sci Sports Exerc 2011;43:1334-1359.

49 Tejero GS, Giraldez Sanchez MA, Cejudo P, et al: Bone health, daily physical activity, and exercise tolerance in patients with cystic fibrosis. Chest 2011;140:475-481.
50 Schneiderman JE, Wilkes DL, Atenafu EG, et al: Longitudinal relationship between physical activity and lung health in patients with cystic fibrosis. Eur Respir J 2014;43:817-823.

51 Conway S, Balfour-Lynn IM, De Rijcke K, et al: European Cystic Fibrosis Society Standards of Care: Framework for the Cystic Fibrosis Centre. J Cyst Fibros 2014;13(suppl 1):S3-S22.

52 Wheatley CM, Wilkins BW, Snyder EM: Exercise is medicine in cystic fibrosis. Exerc Sport Sci Rev 2011;39:155-160.

53 Stevens D, Oades PJ, Armstrong N, et al: A survey of exercise testing and training in UK cystic fibrosis clinics. J Cyst Fibros 2010;9: 302-306.

54 Barker M, Hebestreit A, Gruber W, et al: Exercise testing and training in German CF centers. Pediatr Pulmonol 2004;37:351-355.

55 Cox NS, Elkins MR: Physical training has several benefits for people with cystic fibrosis. $\mathrm{Br}$ J Sports Med 2011;45:835-836.

-56 Selvadurai HC, Blimkie CJ, Meyers N, et al: Randomized controlled study of in-hospital exercise training programs in children with cystic fibrosis. Pediatr Pulmonol 2002;33: 194-200.

57 Klijn PH, Oudshoorn A, van der Ent CK, et al: Effects of anaerobic training in children with cystic fibrosis: a randomized controlled study. Chest 2004;125:1299-1305.

58 Kriemler S, Kieser S, Junge S, et al: Effect of supervised training on FEV1 in cystic fibrosis: a randomised controlled trial. J Cyst Fibros 2013;12:714-720.

-59 Schneiderman-Walker J, Pollock SL, Corey $\mathrm{M}$, et al: A randomized controlled trial of a 3 -year home exercise program in cystic fibrosis. J Pediatr 2000;136:304-310.

60 Moorcroft AJ, Dodd ME, Morris J, et al: Individualised unsupervised exercise training in adults with cystic fibrosis: a 1 year randomised controlled trial. Thorax 2004;59:1074-1080.

61 Hebestreit H, Kieser S, Junge S, et al: Longterm effects of a partially supervised conditioning programme in cystic fibrosis. Eur Respir J 2010;35:578-583.

62 Rovedder PM, Flores J, Ziegler B, et al: Exercise programme in patients with cystic fibrosis: a randomized controlled trial. Respir Med 2014;108:1134-1140.

63 Houston BW, Mills N, Solis-Moya A: Inspiratory muscle training for cystic fibrosis. Cochrane Database Syst Rev 2013;11:CD006112.

64 Newall C, Stockley RA, Hill SL: Exercise training and inspiratory muscle training in patients with bronchiectasis. Thorax 2005;60:943-948.

65 Mandal P, Sidhu MK, Kope L, et al: A pilot study of pulmonary rehabilitation and chest physiotherapy versus chest physiotherapy alone in bronchiectasis. Respir Med 2012;106: 1647-1654.

66 van ZellerM, Mota PC, Amorim A, et al: Pulmonary rehabilitation in patients with bronchiectasis: pulmonary function, arterial blood gases, and the 6-minute walk test. J Cardiopulm Rehabil Prev 2012;32:278-283. 
67 Moran F, Bradley J: Incorporating exercise into the routine care of individuals with cystic fibrosis: is the time right? Expert Rev Respir Med 2010;4:139-142.

-68 Saiman L, Siegel JD, LiPuma JJ, et al: Infection prevention and control guideline for cystic fibrosis: 2013 update. Infect Control Hosp Epidemiol 2014;35(suppl 1):S1-S67.

-69 Silverman M, Hobbs FD, Gordon IR, et al: Cystic fibrosis, atopy, and airways lability. Arch Dis Child 1978;53:873-877.

70 Kaplan TA, Moccia G, McKey RM Jr: Unique pattern of pulmonary function after exercise in patients with cystic fibrosis. Pediatr Exerc Sci 1994;6:275-286.

71 Macfarlane PI, Heaf D: Changes in airflow obstruction and oxygen saturation in response to exercise and bronchodilators in cystic fibrosis. Pediatr Pulmonol 1990;8:4-11.

72 Konstan MW, Doring G, Heltshe SL, et al: A randomized double blind, placebo controlled phase 2 trial of BIIL 284 BS (an LTB4 receptor antagonist) for the treatment of lung disease in children and adults with cystic fibrosis. J Cyst Fibros 2014;13:148-155.

73 Lebecque P, Lapierre JG, Lamarre A, et al: Diffusion capacity and oxygen desaturation effects on exercise in patients with cystic fibrosis. Chest 1987;91:693-697.

74 Ruf K, Hebestreit H: Exercise-induced hypoxemia and cardiac arrhythmia in cystic fibrosis. J Cyst Fibros 2009;8:83-90.

-75 Ferrand RA, Desai SR, Hopkins C, et al: Chronic lung disease in adolescents with delayed diagnosis of vertically acquired HIV infection. Clin Infect Dis 2012;55:145-152.

76 Boas SR: Exercise recommendations for individuals with cystic fibrosis. Sports Med 1997; 24:17-37.

77 Flume PA, Strange C, Ye X, et al: Pneumothorax in cystic fibrosis. Chest 2005;128:720-728.
78 Ruf K, Winkler B, Hebestreit A, et al: Risks associated with exercise testing and sports participation in cystic fibrosis. J Cyst Fibros 2010;9:339-345.

79 Flume PA, Mogayzel PJ Jr, Robinson KA, et al: Cystic fibrosis pulmonary guidelines: pulmonary complications: hemoptysis and pneumothorax. Am J Respir Crit Care Med 2010;182:298-306.

80 Hebestreit H: Exercise in cystic fibrosis; in Mall MA, Elborn JS (eds): Cystic Fibrosis. Sheffield, European Respiratory Society, 2014, pp 203-218.

81 Flume PA, Yankaskas JR, Ebeling M, et al: Massive hemoptysis in cystic fibrosis. Chest 2005;128:729-738.

82 Albert RK, Schuller JL: Macrolide antibiotics and the risk of cardiac arrhythmias. Am J Respir Crit Care Med 2014;189:1173-1180.

83 Sermet-Gaudelus I, Castanet M, Retsch-Bogart G, et al: Update on cystic fibrosis-related bone disease: a special focus on children. Paediatr Respir Rev 2009; 10:134-142.

84 Baris S, Ozen A, Ercan H, et al: Osteoporosis: an ignored complication of CVID. Pediatr Allergy Immunol 2011;22:676-683.

85 Bar-Or O, Blimkie CJ, Hay JA, et al: Voluntary dehydration and heat intolerance in cys tic fibrosis. Lancet 1992;339:696-699.

86 Moran A, Brunzell C, Cohen RC, et al: Clinical care guidelines for cystic fibrosis-related diabetes: a position statement of the American Diabetes Association and a clinical prac tice guideline of the Cystic Fibrosis Foundation, endorsed by the Pediatric Endocrine Society. Diabetes Care 2010;33:2697-2708.

87 Frier BM: Hypoglycaemia in diabetes mellitus: epidemiology and clinical implications. Nat Rev Endocrinol 2014;10:711-722.

88 Cox NS, Alison JA, Holland AE: Interventions for promoting physical activity in people with cystic fibrosis. Cochrane Database Syst Rev 2013;12:CD009448.

89 Baldwin DR, Hill AL, Peckham DG, et al: Effect of addition of exercise to chest physiotherapy on sputum expectoration and lung function in adults with cystic fibrosis. Respir Med 1994;88:49-53.
90 Sutton PP: Chest physiotherapy: time for reappraisal. Br J Dis Chest 1988;82:127-137.

-91 van de Weert-van Leeuwen PB, Arets HG, van der Ent CK, et al: Infection, inflammation and exercise in cystic fibrosis. Respir Res 2013;14: 32.

92 Cholewa JM, Paolone VJ: Influence of exercise on airway epithelia in cystic fibrosis: a review. Med Sci Sports Exerc 2012;44:12191226.

93 Myers LB: An exploratory study investigating factors associated with adherence to chest physiotherapy and exercise in adults with cystic fibrosis. J Cyst Fibros 2009;8:425-427.

94 Sawicki GS, Sellers DE, Robinson WM: High treatment burden in adults with cystic fibrosis: challenges to disease self-management. J Cyst Fibros 2009;8:91-96.

-95 Swisher AK, Erickson M: Perceptions of physical activity in a group of adolescents with cystic fibrosis. Cardiopulm Phys Ther J 2008;19:107-113.

96 Happ MB, Hoffman LA, Higgins LW, et al: Parent and child perceptions of a self-regulated, home-based exercise program for children with cystic fibrosis. Nurs Res 2013;62:305314.

97 Bravata DM, Smith-Spangler C, Sundaram V, et al: Using pedometers to increase physical activity and improve health: a systematic review. JAMA 2007;298:2296-2304.

$>98$ Kuys SS, Hall K, Peasey M, et al: Gaming console exercise and cycle or treadmill exercise provide similar cardiovascular demand in adults with cystic fibrosis: a randomised cross-over trial. J Physiother 2011; 57:35-40.

99 Holmes H, Wood J, Jenkins S, et al: Xbox Kinect represents high intensity exercise for adults with cystic fibrosis. J Cyst Fibros 2013; 12:604-608. 